\section{THE LATEST VOLCANIC ERUPTION IN THE UNITED STATES.}

Is one of the volumes of the Proceedings of the California academy of sciences, Dr. H. W. Harkness describes the cinder-cone and lava-field at Feather Lake, Plumas county, Cal. Writing as I do in the field, and without access to books, I am unable to cite more accurately the description referred to. Dr. Harkness speaks of this volcano as being extremely recent, and mentions the fact that trees killed and half burned by the lava were still standing. Mr. John B. Trask also refers to it, with the statement that the eruption occurred in January, 1850 ; but he does not, so far as I recall, state the source of his information. I regret that I am obliged to depend upon memory alone in referring to these accounts of the outbreak. Within the last week I have had the pleasure of visiting Feather Lake in company with Mr. J. S. Diller, and can fully confirm Dr. Harkness's account of it, and feel confident that Trask's date, January, 1850 , is quite in harmony with all appearances.

Feather Lake, prior to the eruption, was a sheet of water about four or five miles long, lying ten miles east-north-east of Lassen's Peak, say, in latitude $40^{\circ} 34^{\prime}$, and longitude $121^{\circ} 19^{\prime}$; and its altitude is about 5,800 feet above the sea. The vent now covered by a large cinder-cone is situated a little above the western shore. From it there flowed a very thick sheet of basaltic lava, which nearly filled up the lake-basin. The thickness of the flow considerably exceeds 100 feet, and may be as great as 150 feet on the average. The lavafield is about three miles and one-fourth in length, and a mile in width, and half environs the base of the cinder-cone. The cone itself is nearly 600 feet high, and the diameter at the base is about 3,300 feet. It is perfect in form, with a crater in the summit which is not broken down on any side. It is built of scoria and lapilli, the outer layers of which are like coarse sand, giving a smoothness and finish to the surface of the cone which I have seldom seen equalled. Great quantities of fine lapilli and ' ashes' are spread out over the adjoining country to a distance of two miles, and over the lava-sheet itself, quite burying it in some places. The impression of recency is conveyed by every aspect of the cone, of the lava-flow, and of the country round about. The rains have not, as yet, produced even the first trace of a water-channel upon the wonderfully smooth surface of the cone; and the only vegetation which has taken root is a single bush of Ceanothus, near the summit. The lava-sheet is rough and jagged in the extreme, but shows, as yet, no trace of weathering. For a space of four to five hundred yards from the cone, the trees were all killed. Most of them have fallen, and their decayed trunks are still lying on the ground, showing the marks of fire. In thirty-five years (the period assigned by Trask) such decay would be natural. Trees of the same species, felled certainly since 1850 , show elsewhere in the vicinity an equally advanced stage of decay.

Whether the date assigned by 'Trask be the true one or not, the real date cannot be materially older. That the eruption was not at the time a matter of common fame, is readily intelligible ; for the settlement of the northern part of the state did not begin until a year or two afterwards, and it is not probable that any observers except Indians could have witnessed it. Harkness adds, I believe, that it was still hot and feebly 'smoking' in 1852. This may be quite true; for the lava-sheet is an exceptionally thick one, and may have preserved its heat for a long time. And it may also have been seen by many white men in that year ; for one of the routes by which overland emigrants poured into the state was laid in that year along the very base of the cone, and is known to this day as the 'Emigrant trail.'

I am not aware of any volcanic eruption in the United States which is so recent as this one. Vague accounts have been given of eruptions in Oregon, Washington Territory, and southern California within the last twenty years; but they have not been authenticated or confirmed by subsequent observation of the localities. There are lava-flows and cones in Utah, Arizona, and New Mexico, and also in southern California, whose ages must lie within a very few hundred years, but not within the present century. Unless something of the kind more recent is found in some secluded spot hitherto unvisited by the geologist, I think we may safely regard the eruption at Feather Lake as the most recent of any in the country.

A word or two about the country in which this volcano is situated. It is a volcanic region of great extent, covering probably twelve thousand square miles; and Lassen's Peak is its culminating point, and nearly its geographic centre. It is thickly studded with great volcanic piles, and buried thousands of feet deep in ancient lavas. Most of the eruptions are of great antiquity, and those which built the central pile of Lassen's itself are among the 
oldest. Some of the volcanoes are younger, and a considerable number of smaller cones may have been built within a few thousands of years.

C. E. Dutton.

\section{COMETS II AND III OF 1884.}

IT is quite remarkable, that, of the five comets visible during the year 1884 , four should have been periodic, and two of these of short period, and observed apparently for the first time at this return. By short period is generally understood a period of somewhere in the neighborhood of five years, of which we have well - known examples in the comets of Encke (3.3 years), Brorsen (5.5 years), Winnecke (5.7 years), Faye ( 7.4 years), etc., twelve in all.

The new comets referred to are

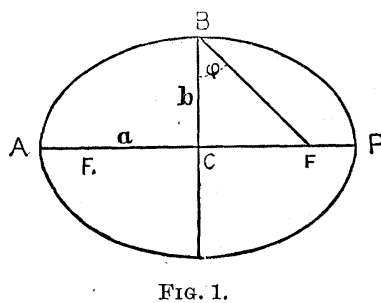
comets II and III of 1884 , - the first discovered by E. E. Barnard of Nashville, Tenn.; and the second, by Max Wolf, a student at Heidelberg. Neither of these comets has been a conspicuous object, - not even visible to the naked eye, I believe, - but they are fair representatives of the class known as 'telescopic' comets.

As I have intimated, the orbit of comet 1884 II (Barnard), is elliptical with a period of about five and a half years. Making allowance for necessary uncertainty, the elements show a certain resemblance to those of DeVico's ' lost comet,' $1844 \mathrm{I}$, which, though certainly elliptical, has not been seen since, if we except a single rather doubtful observation made at Paris in 1855 . The period agrees very well with that determined for DeVico's comet by Brünnow (5.469 years); but Berberich has pointed out that their identity cannot be assumed, for the time elapsed since 1884, forty years, does not correspond to any whole number of revolutions. He notes, also, that the physical appearance would seem to be against this identity ; DeVico's comet, in a similar position with respect to the earth, having been visible to the naked eye. Leverrier thought it very probable that this comet of DeVico's was identical with one observed in 1678 by La Hire; and Laugier and Mauvais concluded that it was identical with the comets $1585,1766 \mathrm{II}$, and 1819 III or IV.
Below are the elements of the two comets, brought together for comparison. DeVico's comet was computed by Brünnow ; Barnard's, by Frisby.

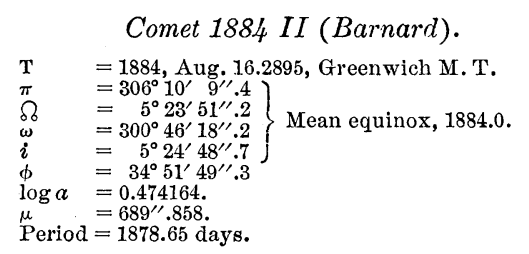

Comet 1844 I (DeVico).

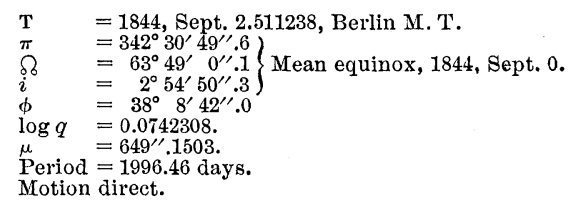

Let me try to show how these elements represent the orbit of a comet, and to give an idea of the shape of this orbit, and its position in space with respect to the sun and earth. By far the most satisfactory way of doing this would be to construct from the elements a cardboard model, which I think can be done with little difficulty from the following directions.

We know, that, in obedience to the law of gravitation, comets must move about the sun in some form of conic section, - the ellipse, parabola, or hyperbola. As a matter of fact, for the majority of comets, the orbit is given as a parabola; a few are known to be elliptic; but it cannot be said with certainty that any are hyperbolic. ${ }^{1}$

We are first to fix the shape and dimensions of the curve, and then its situation with reference to the plane of the ecliptic, in which the earth moves.

Suppose, for a moment, that the orbit is an ellipse, the sun being at

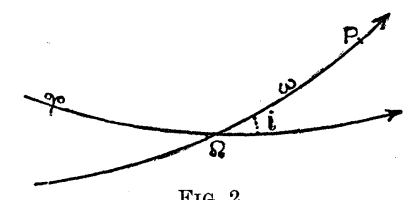

FIG. 2. one focus ( $F$, fig.1). Two of the 'elements' determine the form of the ellipse :-

1. The semi-major axis $C P$, which is denoted by the letter $a$.

2. The eccentricity $e$, the ratio of the distance from the centre to the focus, to the semimajor axis ; that is,

$$
e=\frac{C F}{C P} .
$$

\footnotetext{
1 Newcomb's ' Popular astronomy.'
} 